\section{Violência de gênero e violência sexual em abordagens jornalísticas para ampliação do conhecimento}

\author{
Maria Clara Aquino
}

\section{Resumo:}

$\mathrm{O}$ crescimento da violência sexual está relacionado com outros tipos de violência, como a violência de gênero. A $13^{a}$ edição do Anuário Brasileiro de Segurança Pública mostrou que a cada quatro horas uma menina menor de 13 anos é vítima de violência sexual no Brasil. A maioria é negra e o agressor é normalmente um conhecido. Os dados também mostram aumento do número de assassinatos de LGBTI+. Este artigo faz uma análise de conteúdo das matérias sobre o Anuário e mostra como a conexão entre violência de gênero e violência sexual é exposta à sociedade. $\mathrm{O}$ objetivo é avaliar como o jornalismo pode contribuir para produzir conhecimento sobre conceitos relacionados ao assunto que são de baixa compreensão no âmbito social. São visíveis, no conteúdo analisado, brechas de contextualização sobre os dois tipos de violência. Os dados contidos no relatório são pouco explorados, impedindo que os leitores compreendam não só as origens como também as formas de combate e prevenção dessas violências.

Palavras-chave: Violência de gênero. Violência sexual. Jornalismo

\section{Gender violence and sexual violence in journalistic approaches to expand} knowledge

\begin{abstract}
:
The growth of sexual violence is related to other types of violence, including gender violence. The 13th edition of the Brazilian Yearbook of Public Security showed that every four hours a girl under the age of 13 is a victim of sexual violence in Brazil. Most are black and the aggressor is usually from the family or an acquaintance. The data also show an increase in the number of murders of LGBTI +. This article makes a content analysis of news reports about the Yearbook and shows whether and how the connection between gender violence and sexual violence is exposed to society. The objective is to evaluate how journalism can contribute to producing knowledge about concepts related to the subject that are poorly understood in the social sphere. There are visible gaps in the content analyzed regarding the two types of violence. The data contained in the report are little explored, preventing readers from understanding not only the origins but also the ways of combating and preventing such violence.
\end{abstract}

Keywords: Gender violence. Sexual violence. Journalism
Recebido em: 30.06 .20

Aprovado em: 21.02.21

Maria Clara Aquino

Pesquisadora e docente do Programa de Pós-Graduação em Ciências da Comunicação da Universidade do Vale do Rio dos Sinos. Doutora e mestre em Comunicação e Informação pelo Programa de Pós-Graduação em Comunicação e Informação da Universidade Federal do Rio Grande do Sul.

E-mail: aquino.mariaclara@gmail.com
Estudos em Jornalismo e Mídia v.18, n.1, jan./jun. 2021. ISSNe 1984-6924 


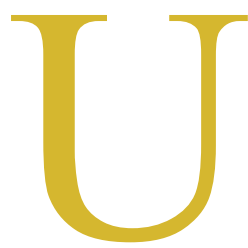

ma entre as tantas dificuldades enfrentadas no combate ao crime de estupro é a inconsistência de dados sobre a quantidade de ocorrências. Oficialmente, estes crimes são subnotificados, por diferentes razões: medo que a vítima tem do agressor; vergonha; falta de delegacias próximas aos locais dos crimes; preconceito e discriminação por parte de familiares, e de policiais no momento do registro da ocorrência, são alguns dos fatores que contribuem para que os dados sobre estupro e outros tipos de violência sexual sejam divergentes da realidade.

Vítimas de violência sexual, na grande maioria das vezes, também são expostas a outros tipos de abuso, seja verbal, físico ou psicológico. Quando procuram ajuda e tentam denunciar o crime, muitas são expostas na imprensa e nas mídias sociais ${ }^{1}$, o que também contribui para a subnotificação de casos de estupro, lesão corporal e outros tipos de abuso. Não é incomum as vítimas sofrerem violência de gênero, ou seja, elas são atacadas por causa da identidade de gênero e/ou por causa da orientação sexual. Desse modo, há, muitas vezes, uma relação entre esses tipos de violência que se agrava diante de questões decorrentes de construtos culturais, como problemas de raça e gênero (LOURO, 1997; DAVIS, 2016) e equívocos construídos com intuitos político-partidários, como a agenda antiaborto do governo Bolsonaro, por exemplo. Para elucidar brevemente, um exemplo é o crime de estupro cometido contra uma transexual ou o feminicídio praticado contra uma lésbica. Nem sempre esses crimes são registrados pela polícia como estupro ou feminicídio devido ao preconceito que a população LGBTI+ sofre; pela carência de denúncia por parte das vítimas em função do medo da discriminação ou dos

${ }^{1}$ A minissérie Unbelivable (2019) conta a história real de uma vítima de estupro desacreditada pela polícia, coagida a retirar a queixa e processada por calúnia contra seu agressor. Duas policiais investigaram o caso e escancararam o descaso da polícia e do poder público com vítimas de estupro (WARKEN, 2019). A exposição das vítimas de violência de gênero que buscam ajuda tem aumentado através das redes digitais. Casos como o de Mariana Ferrer são um exemplo de como as vítimas são expostas online (ALVES, 2020). O promotor responsável pelo caso alegou que durante o ato sexual - ao qual a jovem não estava em condições de consentir a relação - não houve intenção de estuprar, o que caracterizou o "estupro culposo". O réu foi considerado inocente e o caso repercutiu nas redes como um exemplo de exposição da vítima, humilhada pela defesa do réu. Ao final, o réu foi considerado inocente. agressores, entre outros fatores que agravam a subnotificação e contribuem para o pouco conhecimento dos casos por parte da população.

Em 10 de setembro de 2019 foi divulgado a $13^{\mathrm{a}}$ edição do Anuário Brasileiro de Segurança Pública (FÓRUM BRASILEIRO DE SEGURANÇA PÚBLICA, 2019). O documento apresenta dados de 2018 sobre segurança pública no país. Na imprensa, o Anuário foi tema de matérias sobre o crescimento do número dos crimes de estupro no Brasil. Foi a primeira vez que os pesquisadores tiveram acesso ao que chamam de "microdados" (MARTINELLI, 2019) sobre violência sexual, considerando que o estupro é um dos crimes mais subnotificados do país. De acordo com os resultados, a cada quatro horas uma menina de até 13 anos é vítima de violência sexual. Em matérias publicadas pontuando os dados sobre violência sexual e contra a mulher, nos títulos dos textos a palavra "recorde" chama a atenção. Em 2018, o país chegou a ter 66 mil vítimas, o equivalente a 180 estupros por dia, o maior número desse tipo de crime, desde o primeiro relatório, em 2007. O $13^{\circ}$ Anuário mostra que a maioria das vítimas é negra (50,9\%), menor de idade e do sexo feminino. Os casos acontecem dentro de casa e o perfil do agressor é de uma pessoa próxima. A gravidade dos dados assusta e chama a atenção para um problema que não é recente: a violência de gênero atrelada à violência sexual.

Para problematizar essa relação entre os dois tipos de violência, este artigo faz uma observação de como o jornalismo aborda a escalada do estupro a partir da divulgação dos dados do $13^{\circ}$ Anuário. O objetivo é examinar a abordagem das matérias sobre como a conexão entre violência de gênero e violência sexual é exposta para a sociedade. O artigo é parte da fase inicial de um projeto que investiga a cobertura jornalística da violência de gênero, para entender como as práticas jornalísticas podem contribuir para produzir conhecimento sobre conceitos relacionados ao assunto, que são de baixa compreensão no âmbito social. Uma análise de conteúdo temática (BARDIN, 2011) foi feita em 12 matérias publicadas sobre o $13^{\circ}$ Anuário e identificou os principais pontos de abordagem construídos pelos veículos, como eles explicam e contextualizam as violências nos textos publicados. 


\section{A violência de gênero como pauta}

O aumento da visibilidade sobre o tema da violência de gênero se deve, nos últimos anos, a fatores diversos. Vive-se um período de efervescência de movimentos sociais e de militância intelectual contra diferentes tipos de violência contra as mulheres. Ao mesmo tempo em que crescem as forças conservadoras e extremistas, há uma onda de reflexão sobre as relações de gênero, bem como uma agenda de desafios políticos e de reconhecimento de direitos que vão além da luta feminista, por parte da população LGBTI+ (LEAL; CARVALHO; ANTUNES, 2020).

A opressão sexista que recai sobre a mulher historicamente (LOURO, 1997) é um dos principais pontos de partida para a constituição da violência de gênero, atrelada à violência sexual. Apesar da violência sexual não atingir exclusivamente as mulheres, sendo um fenômeno universal, que acomete também homens, as principais vítimas são as mulheres em qualquer período de suas vidas, sendo as jovens e adolescentes as que mais correm esse risco (FACURI ET AL., 2013). Uma observação importante é feita por Davis (2016), quando diz que os estudos sobre as experiências de mulheres negras escravizadas devem ser realizados não apenas pela precisão histórica, mas porque as lições que este tipo de investigação pode revelar sobre a era escravista podem esclarecer muito sobre a luta atual de mulheres negras e de todas as mulheres que até hoje lutam por emancipação nas sociedades.

No que dizia respeito ao trabalho, a força e a produtividade sob a ameaça do açoite eram mais relevantes do que questões relativas ao sexo. Nesse sentido, a opressão das mulheres era idêntica à dos homens. Mas as mulheres também sofriam de forma diferente, porque eram vítimas de abuso sexual e outros maus-tratos bárbaros que só poderiam ser infligidos a elas. A postura dos senhores em relação às escravas era regida pela conveniência: quando era lucrativo explorá-las como se fossem homens, eram vistas como desprovidas de gênero; mas, quando podiam ser exploradas, punidas e reprimidas de modos cabíveis apenas às mulheres, elas eram reduzidas exclusivamente à sua condição de fêmeas (DAVIS, 2016, p. 25).

A situação da mulher negra na época da escravidão reflete como a violência de gênero é vinculada, historicamente, à violência sexual. Não bastassem as mesmas agressões impostas aos homens, como açoitamentos, surras e mutilações, as mulheres também sofriam estupros e outras formas de violência sexual. Como demonstrado no $13^{\circ}$ Anuário, a maioria dos estupros são praticados contra meninas de 10 a 13 anos (28,6\%), das quais 50,9\% são negras. Davis (2016) situa o estupro como uma expressão ostensiva de domínio econômico por parte do proprietário da mulher escrava, uma forma de exercício de poder e controle sobre as vítimas na condição de trabalhadoras. Os agressores eram os feitores, os senhores das casas nas quais tinham de morar, onde eram muitas vezes separadas de seus pais, ainda crianças. De acordo com o Anuário, além de 50,9\% das vítimas serem negras, hoje os agressores são $96,3 \%$ homens, dos quais $75,9 \%$ são conhecidos das vítimas. As considerações de Davis (2016) sobre a relação entre a violência de gênero e a violência sexual aparecem no perfil das vítimas e dos agressores presente no Anuário, confirmando a estruturalidade do problema, que se arrasta por séculos através das relações de poder.

Percebe-se que os dados do Anuário refletem questões históricas determinantes para o que é problematizado aqui na relação entre violência de gênero e violência sexual. Marcadores de raça, classe e gênero são agravantes em uma série de crimes de violência sexual contabilizados por relatórios de pesquisa como o Anuário. Coelho et al. (2020), em uma análise sobre a violência contra a mulher em portais de notícias, identificaram que as mortes e violências sofridas pelas vítimas constituem, "com raras exceções, mais do mesmo corte estatístico das violências genericamente praticadas, com o apagamento das dinâmicas que as promovem” (p. 
120). Isso significa a falta de aprofundamento sobre questões fundamentais para contribuir para a real dimensão do problema da violência de gênero. Os autores, ao explorarem casos diferentes de violência contra a mulher, apontam que mesmo assim "continua-se a operar numa lógica comum de apagamento do gênero enquanto dimensão crucial da violência" (IDEM, p. 136). São constatações graves que identificam a invisibilização dos agressores, eximidos da responsabilidade pela violência, e o deslocamento das vítimas a um segundo plano na cobertura, na medida em que são reduzidas não só quanto à sua dimensão de gênero, mas também enquanto pessoas.

No que tange à cobertura jornalística sobre violência de gênero, a discussão proposta por Moraes e Silva (2019), acerca da "noção de objetividade jornalística e suas relações com a prevalência do machismo e do racismo nas estruturas de produção do conhecimento jornalístico" (p. 3) é mais que necessária, e como elas destacam, precisa ser aproximada da discussão sobre as condições de poder e de saber com base em Foucault (2012), nas quais o jornalismo está embasado e estrutura suas condições epistemológicas como discurso de verdade.

Todos os dias são centenas de exemplos que demonstram o quanto o jornalismo não vem sendo capaz de complexificar fenômenos sociais inspirados pelo machismo e pelo racismo, bem como pelo heterossexismo e o classismo. No Brasil, as desigualdades sociais são marcadamente de raça, de gênero e de classe, colocando às margens gigantescas parcelas da população a partir de sistemas de classificação e hierarquização de diferenças cujas desigualdades se forjam na cultura, nos sistemas simbólicos, em que a linguagem se constitui central. Nesse sentido, o jornalismo vem operando enredado às tramas de poder-saber, reproduzindo valores dominantes a partir das lentes de uma racionalidade excludente (MORAES; SILVA, 2019, p. 12).

A convocação que as autoras fazem ao jornalismo é que, como campo do saber e de poder, não deixe de ser partícipe dos debates sobre a descolonização do pensamento que já vêm acontecendo há alguns anos e que hoje vêm ganhando força e espaço ${ }^{2}$. Almeida (2018) discute o racismo estrutural a partir do colonialismo, como um projeto de universalização com consequências destruidoras e avassaladoras. No seu entendimento, a raça é um conceito que demonstra a incompatibilidade entre a universalidade da razão e o legado iluminista, o que acaba revelando como uma sequência de mortes e destruição decorrentes do colonialismo e da escravidão opera como fundamentos da sociedade contemporânea. Para ele, o racismo é estrutural porque integra a organização da sociedade, em consequência desse processo histórico que introjetou formas de desigualdade e violência que moldam a contemporaneidade.

Subverter a (dita) objetividade jornalística com o intuito de combater o racismo/sexismo epistêmico em que está baseada é o foco deste jornalismo proposto por Moraes e Silva (2019). Não se trata de excluir objetivo ou subjetivo, que se complementam, mas de dar maior legitimidade à subjetividade e observar as posições de classe, gênero, geográficas, raciais e grupais dos jornalistas e dos atores envolvidos nos textos jornalísticos. É preciso considerar a estrutura social circundante, que no caso do Brasil é atravessada e fragmentada pelo classismo, machismo e pelo racismo, para entender como esses marcadores se traduzem caso a caso, entre outras questões que envolvem refletir sobre a autocrítica do próprio campo que privilegia narrativas espetaculares e/ou exotificantes.

A proposta das pesquisadoras vem em um momento em que os números da violência de gênero são crescentes e as pesquisas sobre como o jornalismo tensiona e aborda essa violência tentam identificar o que é privilegiado, apagado, como as

${ }^{2}$ Para um maior aprofundamento sobre o assunto, consulte Hollanda (2020). notícias são construídas e os temas abordados. A crueldade dos crimes e a atividade intensa das pessoas nas redes demanda do jornalismo uma cobertura que vá além da pura notificação. Um exemplo foi o caso do estupro coletivo que aconteceu no 
Rio de Janeiro em 22 de maio de 2016, quando uma jovem de 16 anos foi violentada por 33 homens. As imagens dos abusos foram divulgadas na internet e uma pessoa, que portava as imagens divulgadas nas redes sociais e o vídeo do ocorrido, foi ao Ministério Público fazer a denúncia. A própria vítima soube das imagens pela internet e o jornalismo foi investigar e produzir matérias sobre o caso a partir dos conteúdos que circulavam online. O G1 publicou no dia 27 de maio de 2016 uma matéria cujo título era "Jovem faz exames após suspeita de sofrer estupro coletivo no Rio". O uso da palavra "suspeita" mobilizou os comentários nas redes, como analisa Mousinho (2016), mostrando que os comentários mais curtidos em torno dessa matéria expressavam aversão ao crime e defesa da vítima. Há, no entanto, nesse caso, uma diversidade de manifestações que revelam traços de culpabilização da vítima, mostrando como o debate gerado nas redes muitas vezes reforça a violência de gênero e exige do jornalismo um posicionamento mais assertivo ou combativo a esse tipo de comportamento, nos textos das matérias. Santos e Maradei (2016), ao analisarem a hashtag \#estupro nesse mesmo caso do estupro coletivo do Rio de Janeiro, identificaram como o machismo despontou nos comentários, ao mesmo tempo em que foi constatada pouca solidariedade à vítima.

Em entrevista ao site objETHOS, Moraes fala sobre a relação do jornalismo de subjetividade com uma postura ética e ativista do jornalismo (PAUL, 2020). Ao lidar com casos como esse do estupro coletivo, por exemplo, o jornalismo se depara com questões de realidades diversas, que mobilizam atores e situações distintas. Há o tensionamento da questão da ética que faz, como ela explica, com que os jornalistas se percebam como seres dinâmicos. São nesses momentos que a subjetividade do jornalismo é acionada para que orientações e perspectivas possam adentrar os textos, através de posicionamentos explícitos e enfoques que não destaquem a violência, e promovam a transformação de um jornalismo calcado em preceitos positivistas e binários, simplificadores e opressores para a construção de matérias que permitam uma leitura desconstrutiva do racismo, machismo e da misoginia, muitas vezes enraizados nas redações, como já analisado por Silva (2014).

Dados de uma reportagem do G1 DF (RODRIGUES, 2017) mostram que, em 2016, a cada duas horas e meia, uma mulher no Brasil sofreu estupro coletivo; só naquele ano foram registrados 3.526 casos. Em cinco anos, o registro de estupros coletivos cresceu $124 \%$. Os dados sobre a violência contra LGBTI+s também são alarmantes. Entre 1963 e 2018 foram 8.027 assassinatos de pessoas LGBTI+s no Brasil. O número é alto, porém são apenas os casos notificados. Muitas vítimas não registram os crimes por medo dos agressores, há casos que não são registrados porque a vítima sofre preconceito no ambiente da delegacia e outros em que o registro não se configura de forma correta pela inconsistência na tipificação do crime. Nesse sentido, o medo compartilhado por essas pessoas é impulsionado pela questão de gênero, que não por coincidência, revela a motivação dos agressores: o gênero e/ou a orientação sexual.

Os problemas enfrentados pelas vítimas são agravados quando a ignorância e o desconhecimento sobre questões de gênero e sexualidade são potencializados pela ação de agentes políticos e/ou religiosos, ou de alas conservadoras da sociedade que estabelecem e agem para fortalecer discursos que prejudicam a luta contra a violência de gênero e as pautas feministas e LGBTI+s. É o caso do que tem sido denominado equivocadamente de "ideologia de gênero". A expressão carrega um sentido pejorativo, pelo qual setores conservadores da sociedade se manifestam contra pessoas e ações que visam promover o debate sobre questões de gênero e outros tópicos relacionados à sexualidade, inclusive no contexto das escolas, como se percebe na discussão a respeito do movimento Escola sem Partido ${ }^{3}$. O movimento, crítico à educação sexual nas escolas, confunde a discussão sobre gênero, não esclarecendo sobre conceitos como identidade de gênero e orientação sexual, já que ignora as diferenças entre os mesmos.

${ }^{3}$ Trata-se de um movimento iniciado em 2004 pelo advogado Miguel Nagib, que luta contra o que denominam "doutrinação ideológica” nas escolas. O movimento entende que as escolas doutrinam os alunos ao obrigá-los a ficarem em sala de aula e por isso queriam a implantação de um cartaz nas salas expondo os deveres do professor e os direitos dos alunos, entre os quais estaria o de não serem doutrinados. O movimento foi um dos principais responsáveis pela circulação da expressão "ideologia de gênero", ao defender que questões sobre gênero e sexualidade não sejam discutidas em sala de aula, apenas no âmbito familiar. 
De acordo com Miskolci e Campana (2017), a expressão, da maneira como é posta, divide os envolvidos, promove a polarização entre grupos, colocando as pessoas em lados opostos. A recuperação histórica que os autores fazem da expressão identifica como o gênero, quando utilizado como ferramenta de poder, vem sendo apropriado de forma perversa, por grupos políticos, religiosos e laicos, para ameaçar a sociedade, incutindo uma espécie de "pânico moral", através de um "campo discursivo de ação" (MISKOLCI; CAMPANA, 2017). A palavra "ideologia" aciona imediatamente no indivíduo a premissa de que é necessário adotar um posicionamento perante um embate sobre uma ideia que sequer é compreendida por muitos como algo discutido no campo científico como uma questão que concerne à subjetividade humana. "A luta contra a 'ideologia de gênero' é uma forma de resistência contra os recentes avanços que vêm se dando na América Latina em matéria de direitos sexuais e reprodutivos" (MISKOLCI; CAMPANA, 2017, p. 728). Esse tipo de mobilização ganha força no contexto digital. Recuero e Soares (2013) analisam como o discurso mediado pelo computador é capaz de reforçar estigmas sociais, causando em determinados casos uma naturalização da violência no contexto das redes sociais. A ignorância sobre o assunto aumenta à medida que a expressão ganha força ao se difundir através de conversações e redes de espalhamento que se maximizam nas redes digitais.

O embate ideológico é travado diante de uma crítica feminista que cresce como movimento teórico e social (HALL, 1997). O pensamento feminista, ao combater argumentos e raciocínios dicotômicos e binaristas, vai promover o debate sobre gênero e sexualidade através de outras formas de reflexão e tensionamento. As relações de poder (FOUCAULT, 2012) tornam-se fundamentais como categoria de análise para os estudos sobre gênero, como explicam Moraes e Silva (2019). Além disso, as vertentes decoloniais, aprofundadas pelas pesquisadoras, "que compartilham de uma epistemologia da alteridade (PELUCIO, 2012) e de uma política da diferença (MISKOLCI, 2012)" (MORAES; SILVA, 2019, p. 7), trazem novos ângulos para se pensar sobre "a produção discursiva da diferença, feita através de processos linguísticos de significação em redes de poder-saber” (IDEM, p. 7). Através dessa complexificação das noções de diferença, elas destacam a possibilidade de se pensar nas "interseccionalidades entre os diferentes marcadores e suas implicações nas formas de assujeitamento normativo e das hierarquias de poder produzidos por regimes de verdade em que a produção de conhecimentos é chave” (IDEM, p. 7).

\section{Métodos, análise e discussão}

O $13^{\circ}$ Anuário foi divulgado no dia 10 de setembro de 2019. Desde a primeira edição, em 2007, o anuário tem como objetivo contribuir para a melhoria da qualidade de dados sobre a segurança pública no país. As informações do relatório são fornecidas pelas secretarias estaduais de segurança pública, pelo Tesouro Nacional, pelas polícias civis, militares e federal, entre outras fontes oficiais. São 90 páginas com pouco texto, muitos números, que demandam um longo tempo de análise para se abstrair apontamentos sobre o contexto da violência e da segurança pública no país. Diante desse tipo de publicação, cabe aos jornalistas que cobrem pautas desse tipo se debruçarem sobre materiais como este para trabalhar com os dados e traduzir o montante de números em conteúdo inteligível para os leitores. Relatórios dessa densidade, que contextualizam a problemática abordada, permitem o estabelecimento de conexões entre os dados, problemas e situações complexas e diversificadas, o que torna a cobertura jornalística a partir desses materiais diferenciada da cobertura feita sobre violência sexual e de gênero que não parte desse tipo de conjunto de dados.

A quantidade de dados permite a elaboração de matérias que ultrapassem o reducionismo e a simplificação dos temas, a partir de pautas geradas pela própria 
divulgação dos relatórios e da relevância dos dados que apresentam. Essas oportunidades de cobertura já diferenciam esse tipo de matéria do cotidiano de cobertura sobre violência de gênero e violência sexual, pois contextualizam um cenário específico e abrangem a amplitude da complexidade do problema. Espera-se, além da exposição dos números, apontamentos que evidenciem mais do que a gravidade da violência, as especificidades dos cenários onde ela acontece, as vozes das vítimas, suas características, os elementos necessários para que os leitores possam identificar quando os crimes são motivados por questões de gênero e orientação sexual e possam entender quando, onde, como e por que essa violência acontece.

A primeira busca por matérias foi feita inserindo-se o título do documento "13 Anuário Brasileiro de Segurança Pública" no Google, em seguida clicando no link "notícias" nas opções de pesquisa. O número obtido foi de 4.770 resultados, todos de notícias textuais. Verificou-se no âmbito das três primeiras páginas a ocorrência de matérias que abordavam a questão da escalada da violência no país. Em uma segunda busca, foi acrescentado o termo "estupro" ao título do documento, sendo a pesquisa feita a partir de "13 Anuário Brasileiro de Segurança Pública estupro". O número diminuiu para 1.670 resultados. Nas duas primeiras páginas foram encontradas algumas das mesmas matérias que apareceram na busca anterior, entre outras, que eram mais direcionadas para os dados do documento que abordavam a violência sexual. Dessa forma, optou-se por selecionar matérias que aparecessem tanto na primeira quanto na segunda busca, mas que fossem sobre o crime de estupro.

Para selecionar as matérias, além de delimitar as que abordavam o crime de estupro, manteve-se o foco naquelas que foram publicadas, em veículos jornalísticos, perto da data em que o Anuário foi divulgado, no dia 11 de setembro de 2019. Dessa forma, chegou-se um corpus de 12 matérias (Tabela 1), que tiveram seus conteúdos analisados a partir de uma perspectiva temática (BARDIN, 2011).

Tabela 1: Enfoques das matérias analisadas

\begin{tabular}{|c|c|c|c|}
\hline Data & Veículo & Título da matéria & Enfoque \\
\hline $10 / 09 / 19$ & $\begin{array}{l}\text { Agência Brasil } \\
\text { (COSTA, 2019) }\end{array}$ & $\begin{array}{l}\text { Estupro bate recorde e } \\
\text { maioria das vítimas é } \\
\text { de meninas até } 13 \text { anos }\end{array}$ & $\begin{array}{l}\text { Crimes de estupro; víti- } \\
\text { mas meninas de até } 13 \\
\text { anos; perfil do agressor; } \\
\text { feminicídio. }\end{array}$ \\
\hline $10 / 09 / 19$ & $\begin{array}{l}\text { G1 (ACAY- } \\
\text { ABA; REIS, } \\
\text { 2019) }\end{array}$ & $\begin{array}{l}\text { País tem recorde nos } \\
\text { registros de estupros; } \\
\text { casos de injúria racial } \\
\text { aumentam } 20 \%\end{array}$ & $\begin{array}{l}\text { Recorde no registro dos } \\
\text { crimes de estupro; injúria } \\
\text { racial; violência de gênero; } \\
\text { crimes de ódio. }\end{array}$ \\
\hline $10 / 09 / 19$ & $\begin{array}{c}\text { O Globo (RI- } \\
\text { BEIRO, 2019a) }\end{array}$ & $\begin{array}{l}\text { Brasil registrou recorde } \\
\text { de casos de estupro em } \\
\text { 2018, segundo estudo }\end{array}$ & $\begin{array}{l}\text { Recorde de estupros no } \\
\text { país; perfil da vítima e do } \\
\text { agressor; relatos e histórias. }\end{array}$ \\
\hline $10 / 09 / 19$ & $\begin{array}{c}R 7 \text { (SACHE- } \\
\text { TO, 2019) }\end{array}$ & $\begin{array}{c}\text { Brasil tem quatro } \\
\text { meninas de até } 13 \text { anos } \\
\text { estupradas por hora, } \\
\text { diz estudo }\end{array}$ & $\begin{array}{l}\text { Crimes de estupro; vítimas } \\
\text { meninas de até } 13 \text { anos; } \\
50,9 \% \text { negras; violência } \\
\text { doméstica; violência de } \\
\text { gênero. }\end{array}$ \\
\hline $11 / 09 / 19$ & $\begin{array}{l}\text { A Crítica (AM- } \\
\text { ORIM, 2019) }\end{array}$ & $\begin{array}{c}\text { Amazonas registra } \\
\text { aumento de casos de } \\
\text { violência contra mulher }\end{array}$ & $\begin{array}{l}\text { Aumento de casos de } \\
\text { violência contra a mulher; } \\
\text { vítimas entre } 12 \text { e } 14 \text { anos; } \\
\text { violência doméstica. }\end{array}$ \\
\hline $11 / 09 / 19$ & $\begin{array}{c}\text { El País } \\
\text { (GORTÁZAR, } \\
\text { 2019) }\end{array}$ & $\begin{array}{c}\text { A cada hora quatro } \\
\text { meninas com menos de } \\
13 \text { anos são estupradas } \\
\text { no Brasil }\end{array}$ & $\begin{array}{l}\text { Número de estupros por } \\
\text { hora no país; vítimas meni- } \\
\text { nas menores de } 13 \text { anos; } \\
\text { violência no Brasil. }\end{array}$ \\
\hline
\end{tabular}




\begin{tabular}{|c|c|c|c|}
\hline $11 / 09 / 19$ & $\begin{array}{l}\text { NSC Total/ A } \\
\text { Notícia (RE- } \\
\text { DAÇÃO AN, } \\
\text { 2019) }\end{array}$ & $\begin{array}{l}\text { Polícia prende suspeito } \\
\text { de estuprar criança de } \\
\text { dois anos em Joinville }\end{array}$ & $\begin{array}{l}\text { Prisão de suspeito de estu- } \\
\text { pro; dados do anuário sobre } \\
\text { crimes de estupro; vítimas } \\
\text { menores de } 13 \text { anos. }\end{array}$ \\
\hline $11 / 09 / 19$ & $\begin{array}{c}\text { Outras Pala- } \\
\text { vras (MATHI- } \\
\text { AS; TORRES, } \\
\text { 2019) }\end{array}$ & $\begin{array}{l}\text { O novo recorde de } \\
\text { violência sexual }\end{array}$ & $\begin{array}{c}\text { Recorde de violência sex- } \\
\text { ual; número de estupros; } \\
\text { vítimas meninas de até } 13 \\
\text { anos. }\end{array}$ \\
\hline $12 / 09 / 19$ & $\begin{array}{l}\text { Yahoo! Notí- } \\
\text { cias/ Alma Pre- } \\
\text { ta (SIMÕES, } \\
\text { 2019) }\end{array}$ & $\begin{array}{l}\text { Crianças negras são } \\
\text { as maiores vítimas de } \\
\text { estupro no Brasil }\end{array}$ & $\begin{array}{l}\text { Crianças negras maiores } \\
\text { vítimas de estupros no } \\
\text { país; vítimas menores de } 14 \\
\text { anos; hiperssexualização na } \\
\text { infância. }\end{array}$ \\
\hline $15 / 09 / 19$ & $\begin{array}{l}\text { HuffPost Brasil } \\
\text { (MARTINEL- } \\
\text { LI, 2019) }\end{array}$ & $\begin{array}{l}\text { Recorde de estupros no } \\
\text { Brasil escancara neg- } \\
\text { ligência com crimes de } \\
\text { violência sexual }\end{array}$ & $\begin{array}{l}\text { Recorde de estupros no } \\
\text { país; negligência com } \\
\text { crimes de violência sexu- } \\
\text { al; entrevista com Samira } \\
\text { Bueno. }\end{array}$ \\
\hline $01 / 10 / 19$ & $\begin{array}{c}\text { Época (RI- } \\
\text { BEIRO, 2019b) }\end{array}$ & $\begin{array}{l}\text { Coluna: Sete em cada } \\
\text { dez vítimas de estu- } \\
\text { pros em São Paulo são } \\
\text { vulneráveis }\end{array}$ & $\begin{array}{l}\text { Vítimas menores de idade; } \\
\text { perfil do agressor; educação } \\
\text { sexual. }\end{array}$ \\
\hline $07 / 11 / 19$ & $\begin{array}{l}\text { Diário da } \\
\text { Manhã (LE- } \\
\text { MES, 2019) }\end{array}$ & $\begin{array}{c}\text { Quatro meninas com } \\
\text { menos de } 13 \text { anos são } \\
\text { estupradas a cada hora } \\
\text { no Brasil }\end{array}$ & $\begin{array}{c}\text { Vítimas menores de } 13 \\
\text { anos estupradas por hora } \\
\text { no país; perfil do agressor; } \\
\text { vítimas negras. }\end{array}$ \\
\hline
\end{tabular}

Fonte: autoria própria.

A partir de uma leitura aprofundada das matérias selecionadas, foi feito um levantamento de ocorrências recorrentes nos textos, caracterizando uma linha de abordagem sobre o assunto violência sexual atrelada à violência de gênero. Há uma linha de abordagem em comum nas 12 matérias. A reportagem publicada pelo NSC Total/ A Notícia, ainda que seja sobre a prisão de um suspeito de um crime, trata sobre os dados do Anuário, e por isso foi incluída no corpus.

A palavra "recorde" aparece em seis das 12 matérias. Em todos os casos o termo é utilizado para se referir ao número de estupros no Brasil em 2018, sendo, em alguns deles, atrelado a uma ou outra questão abordada na matéria, como no G1, que menciona a injúria racial, e na Agência Brasil, que aborda a idade das vítimas. "Estupro" e/ou "violência sexual" ou "contra a mulher" estão em todos os títulos, revelando assunto das matérias que exploram os dados do Anuário. Nesse sentido, as fontes são outro tópico que se sobressai nas matérias. Considerando que os textos têm como pauta os dados do Anuário, as fontes principais são inicialmente os dados em si, o relatório de pesquisa, e as pessoas envolvidas na produção do documento. Samira Bueno, diretora executiva do Fórum Brasileiro de Segurança Pública, é a coordenadora geral do Anuário, junto com Renato Sérgio de Lima, diretor do Fórum. Em entrevista ao HuffPost Brasil, na mesma matéria analisada, Samira demonstra seu posicionamento sobre a violência sexual no país:

Eu acredito que parte do aumento [de registros] acontece porque o tema da violência de gênero entrou na agenda da imprensa, do Judiciário e do movimento feminista. Fruto disso é um movimento de mulheres que se sentem mais seguras para falar sobre isso (...) o Estado tem responsabilidade de intervir. (...) Não podemos achar que por ser uma violência que acontece no ambiente doméstico, o Estado não tem nada a ver com isso. (...) Ora, se a maior parte das vítimas é criança, a gente não vai superar essa questão se a gente não falar 
de educação sexual nas escolas. Até porque muitas dessas crianças só vão entender o que é uma violência falando sobre ela, entendendo o que pode e o que não pode. Essa ideia de que a família é o único ator legítimo para educar sobre sexualidade é uma falácia. Enquanto acharmos que falar sobre sexualidade é prerrogativa exclusiva da família, estamos incentivando o estupro no Brasil. (MARTINELLI, 2019)

Como mulher e coordenadora do documento, Samira é fonte importante, pois também atua na elaboração do Atlas da Violência, outro documento de pesquisa que informa sobre o status da violência no país. Samira é fonte nas matérias sobre o Anuário. No G1 é entrevistada na reportagem da Globo News, cujo vídeo aparece logo no início do texto, e destaca a falta de prioridade do governo para tratar da violência contra a mulher; necessidade de educação sexual nas escolas e também de meninos, para qualificar o debate sobre equidade de gênero. $\mathrm{O}$ texto também traz outras citações de Samira.

O HuffPost Brasil entrevista Samira, oferecendo aos leitores, além de uma leitura mais ampla dos dados, uma percepção mais apurada de seu posicionamento, como transcrito acima. Em trechos da conversa expostos na matéria, Samira tece críticas ao que chama de "sociedade moralista" e mostra como ainda é preciso evoluir como sociedade para dar conta do problema:

A gente, enquanto sociedade, ainda é muito moralista em relação à violência sexual. O primeiro passo que se faz quando da denúncia deste tipo de crime, seja por uma mulher ou menina, é duvidar da vítima. Eu acredito que parte do aumento [de registros] acontece porque o tema da violência de gênero entrou na agenda da imprensa, do Judiciário e do movimento feminista. Fruto disso é um movimento de mulheres que se sentem mais seguras para falar sobre isso, o que, de certa forma, estimula a denúncia. Mas hoje, ainda, se uma mulher chega à delegacia com o olho roxo, ela é atendida de uma forma; se ela chega alegando que foi estuprada, e essa violência não tem resquícios e provas, cria-se um ciclo de revitimização (MARTINELLI, 2019).

No Yahoo! Notícias/ Alma Preta, um trecho do Anuário que Samira escreve junto com Carolina Pereira e Cristina Neme, outras duas pesquisadoras, é citado para abordar o recorde de estupros: "Esse quadro se torna ainda mais grave na medida em que os depoimentos de crianças com certa frequência são questionados por falta de credibilidade, além do silêncio e por vezes cumplicidade que envolvem outros parentes próximos". O El País utiliza apenas uma citação de Samira, sobre as mortes de adolescentes nas favelas, comentando dados do Anuário sobre assassinatos, e não sobre violência sexual. No $O$ Globo, Samira é citada brevemente, quando a matéria destaca o tabu em torno do assunto e a dificuldade relacionada à subnotificação dos crimes de estupro. As falas de Samira são os apontamentos mais contundentes sobre os problemas acarretados pela violência sofrida pelas mulheres que aparecem nas matérias. Ainda que outras pesquisadoras do Anuário tenham sido citadas em outras matérias, além dos dados que são elencados, Samira explica as causas e indica maneiras responsáveis que podem amenizar a situação bastante problemática. O Diário da Manhã e o site Outras Palavras não trazem nenhuma pessoa como fonte; ambos exploram apenas os dados do Anuário. Apenas no G1 parentes ou pessoas próximas de vítimas foram entrevistados. A escuta e a visibilidade para as vozes das vítimas e de pessoas próximas a elas, como parentes e amigos, ajudam na visibilização do problema, auxiliam na conexão das que são diretamente e indiretamente afetadas pelos crimes e agressões, contribuindo para a constituição de redes de apoio e ajuda mútua. Quando as matérias concedem espaço para esses depoimentos, contribuem para a desmitificação do assunto, para a desconstrução do sentimento de vergonha, muitas vezes manifestado por vítimas e seus familiares. A invisibilização das vítimas, total nesse caso analisado, contribui para a subnotificação. Quanto menos as vítimas enxergam umas às outras, menos entendem esses espaços midiáticos como legítimos para expor suas histórias, internalizando ainda mais a falsa ideia de culpa que sentem pelas agressões que sofrem.

${ }^{4}$ Carolina Pereira e Cristina Neme aparecem nas matérias do G1, Thandara Santos, conselheira do FBSP, na matéria do $R 7$, junto com um juiz da Vara da Infância e da Juventude. Uma delegada especializada em crimes contra a mulher aparece na matéria do A Crítica; a coordenadora do núcleo de enfrentamento às violências de gênero do Instituto Avon é citada como fonte em estudo publicado pela universidade norte-americana Georgetown Law School, em 2017. 
As abordagens dos veículos, na medida em que realçam determinados números, fazem uso de termos, expressões e fontes que dão a entender qual ênfase querem dar na matéria, porém pouco aprofundam o assunto e, por vezes, esvaziam o significado do que se mede. É o caso das matérias que utilizam o termo "recorde" em seus títulos, por exemplo. Nesses casos, é perceptível o objetivo de chamar a atenção do leitor para a gravidade dos números. O documento também utiliza a palavra "recorde" três vezes, ainda que em nenhuma das vezes para se referir a crimes de estupro. O uso da palavra é inadequado, perde o sentido, pois é óbvio que nenhuma cidade, estado ou país compete por um número que indica o crescimento da violência, no caso os crimes de estupro.

$\mathrm{Na}$ fala de Samira veiculada no vídeo da matéria da Globo News, no G1, ela destaca que todos os crimes de violência letal diminuíram, diante do aumento do número de casos de violência contra a mulher. Essa informação é absolutamente importante diante dos dados e da situação de violência do país. Trata-se de um dado que é revelado pelo Anuário e que o jornalismo tem a obrigação de tornar notícia, pela gravidade e pelas informações correlacionadas. O G1 expõe essa questão logo de início, ampliando os outros parágrafos do texto sempre a partir desta perspectiva comparativa com outros crimes de violência letal. A Crítica, do Amazonas, também faz esse apontamento no início da matéria. Espera-se, no entanto, uma ampliação das matérias sobre como a questão do gênero é fator determinante em vários casos e como o poder público deve agir para combater esse problema. Esse tipo de abordagem é inexistente, salvo as citações de Samira Bueno.

Os focos das publicações são a idade das vítimas, menores de 13 anos, enquadradas como vulneráveis, e o perfil do agressor, que em muitos casos é próximo, um parente, e muitas vezes o próprio pai. Chama a atenção o fato de que em apenas dois veículos foram levantadas questões sobre relações de poder e desigualdade de gênero como motivadores dos crimes de estupro, e é nesse tipo de abordagem que o jornalismo de subjetividade (MORAES; SILVA, 2019) precisa ser inserido. Há matérias que abordam a necessidade de campanhas de conscientização e de educação sexual nas escolas, para proteger as crianças de possíveis ataques, ensinando-as a identificarem os agressores e para que saibam como pedir ajuda fora de casa, local onde muitas vezes a violência acontece. Em apenas duas matérias, essas campanhas de conscientização e de educação sexual são atreladas a comentários sobre a educação de meninos. Outro tópico frequentemente abordado nos textos, que vem dos dados do Anuário, é a subnotificação dos crimes.

A falta de articulação entre os marcadores de raça e classe também chama a atenção. Um dado apontado pelo Anuário é que 50,9\% das vítimas de estupro são negras. A palavra "racismo" aparece em apenas uma das matérias analisadas, na do El País, quando o texto fala sobre o racismo estrutural com relação aos dados gerais sobre violência apresentados pelo relatório, sem explicar o que significa a expressão. As menções à questão racial são apenas numéricas, com quase nada de aprofundamento ou problematização, sem praticamente uma diferenciação entre as mortes de mulheres brancas e negras, nem sobre as classes sociais.

\section{Apontamentos finais}

Diante da proposta de refletir sobre a abordagem jornalística acerca da violência de gênero e da violência sexual, são visíveis brechas na contextualização dos dois tipos de violência. Há um padrão que desponta nos textos e é possível afirmar que fazem um tratamento resumido sobre o tema, diante do extenso conjunto de dados do relatório - considerando ainda outras fontes disponíveis. É nítida a concentração em dados que apontam a gravidade de um problema que 
não é recente, e que vem intensificando-se em uma faixa etária, com características que indicam o perfil não só da vítima, mas do agressor. Os dados expõem um sistema social com problemas de diferentes naturezas, mas o jornalismo não trabalha esses dados a ponto de prover recursos aos leitores para que estes identifiquem as causas dessas violências.

As tentativas que o jornalismo faz de apontar possíveis soluções ou responsáveis capazes de agir para amenizar os problemas são expostas de forma pontual, desconectadas entre si, descontextualizadas e pouco aprofundadas. Há pouca exploração dos dados do Anuário de modo relacionado com tópicos que tratam sobre a origem dos crimes e com ações capazes de combatê-los. Essa falta de conexão entre o que motiva os crimes, de esclarecimento sobre conceitos como identidade de gênero e orientação sexual e de abordagem sobre tópicos diretamente relacionados à ocorrência ou à subnotificação dos crimes são fatores que contribuem para o baixo nível de conhecimento das pessoas sobre violência de gênero atrelada à violência sexual. $O$ silenciamento das vítimas potencializa não só o desconhecimento sobre as causas dessas violências como a subnotificação e até mesmo a legitimação das violências. A análise evidencia abordagens que pouco, ou quase nada, divulgam sobre conceitos relacionados ao assunto que, como exposto no texto, são de baixa compreensão no âmbito social; muitas vezes incompreendidos ou difundidos de maneira equivocada, como acontece com a expressão “ideologia de gênero". Sobre as 12 matérias, não há diferença evidente quando assinadas por repórter homem ou mulher. O que é notório é a preocupação dos jornalistas em chamar a atenção para um dado em específico: mostrar que há um crescimento do número de estupros. A utilização da palavra "recorde" não é feita com a intenção de colocar o país em destaque no sentido positivo, obviamente. Bater o recorde do número de estupros significa que há um problema bastante sério, que não vem sendo contextualizado e problematizado adequadamente pelo jornalismo. O uso da palavra "recorde" indica uma tentativa de chamar a atenção dos leitores, provavelmente.

O foco nos números problemáticos acaba evidenciando a carência de informações que permitam aos leitores compreenderem, além das origens dessas violências, formas de combate e prevenção. Mencionar a parcela de vítimas negras sem contextualizar as raízes do racismo não contribui para a conscientização sobre esse elemento como parte da estrutura da sociedade (ALMEIDA, 2018). A dispersão desses pontos mostra que há, como num esquema de pirâmide invertida, uma exposição inicial dos dados alarmantes, e posteriormente alguns dos tópicos importantes que podem abastecer os leitores com conhecimento sobre o problema, com informações úteis para ajudar as vítimas, para combater o crime, para identificar possíveis agressores e educar crianças. Em uma matéria encontra-se algo sobre relações de poder; em outra, um trecho sobre educação sexual; outros veículos vão destacar o perfil do agressor, mostrando a necessidade de uma educação que se inicia na infância de meninos. Dois veículos abrem espaço para as vítimas, os outros sequer o fazem. Não há, no entanto, em 12 textos, uma matéria que, de maneira consistente, traga uma abordagem que conecte essas questões que envolvem o tema, que aparecem separadamente em um e outro texto, promovendo uma contextualização abrangente sobre toda a dimensão do problema.

É urgente a configuração de um jornalismo que seja subjetivo e posicionado (MORAES; SILVA, 2019) a ponto de tensionar tópicos sobre racismo, machismo, homofobia e outros agravantes da violência sexual atrelada à violência de gênero. A explicação de termos e conceitos essenciais para o conhecimento sobre os cenários é importante para que pesquisas como a do Anuário e do Atlas, entre outras, sejam visibilizadas para a sociedade, permitindo que todos os tipos de violência sejam devidamente enxergados e combatidos. 


\section{Referências}

ACAYABA, Cíntia; REIS, Thiago. País tem recorde nos registros de estupros; casos de injúria racial aumentam 20\%. G1, São Paulo, 10 setembro 2019. Disponível em: https://g1.globo.com/sp/sao-paulo/noticia/2019/09/10/pais-tem-recorde-nosregistros-de-estupros-casos-de-injuria-racial-aumentam-20percent.ghtml.Acesso em: 25 mar. 2021.

ALMEIDA, Silvio Luiz de. O que é racismo estrutural? Belo Horizonte: Letramento, 2018.

ALVES, Schirlei. Julgamento de influencer Marina Ferrer termina com tese inédita de 'estupro culposo' e advogado humilhando jovem. The Intercept Brasil, [s.l.], 3 novembro 2020. Disponível em: https://theintercept.com/2020/11/03/influencer-mariana-ferrer-estupro-culposo/. Acesso em: 25 mar. 2021.

AMORIM, Daniel. Amazonas registra aumento de casos de violência contra mulher. A Crítica, Manaus, 11 setembro 2019. Disponível em: https://www.acritica. $\mathrm{com} /$ channels/cotidiano/news/amazonas-registra-aumento-de-casos-de-violencia-contra-mulher. Acesso em: 25 mar. 2021.

BARDIN, Laurence. Análise de Conteúdo. São Paulo: Edições 70, 2011.

BLAKE, Jamilia J.; EPSTEIN, Rebecca. Listening do Black Women and Girls: Lived Experiences of Adultification Bias. Georgetown Law Center on Powerty and Inequality. Initiative on Gender Justice \& Oportunity. 2017. Disponível em: https://www.law.georgetown.edu/poverty-inequality-center/wp-content/uploads/sites/14/2019/05/Listening-to-Black-Women-and-Girls.pdf. Acesso em: 20 mai. 2021.

COELHO, Dalila, et. al. Violência contra mulher em portais de notícias: (des)continuidades narrativas na cobertura jornalística. In: LEAL, Bruno S.; CARVALHO, Carlos A. de; ANTUNES, Elton. Um problema cotidiano [recurso eletrônico]: jornalismo e violência contra mulher no Brasil. Belo Horizonte: Faculdade de Filosofia e Ciências Humanas, 2020.

COSTA, Gilberto. Estupro bate recorde e maioria das vítimas é de meninas até 13 anos. Agência Brasil, Brasília, 10 setembro 2019. Disponível em: http://agenciabrasil.ebc.com.br/geral/noticia/2019-09/estupro-bate-recorde-e-maioria-das-vitimas-sao-meninas-de-ate-13-anos. Acesso em: 25 mar. 2021.

DAVIS, Angela. Mulheres, raça e classe. São Paulo: Boitempo Editorial, 2016.

FACHINNI, Regina; FERREIRA, Carolina B. C. Feminismos e violência de gênero no Brasil: apontamentos para o debate. Ciência e Cultura, Campinas, v. 68, n. 3, p. 4-5, jul./set. 2016. doi:10.21800/2317-66602016000300002.

FACURI, Cláudia de O. et al. Violência sexual: estudo descritivo sobre as vítimas e o atendimento em um serviço universitário de referência no Estado de São Paulo, Brasil. Cadernos de Saúde Pública, Rio de Janeiro, v. 29, n. 5, p. 889-898, 2013. doi:10.1590/S0102-311X2013000500008. 
FÓRUM BRASILEIRO DE SEGURANÇA PÚBLICA. Anuário Brasileiro de Segurança Pública 2019. ISSN 1983-7364, ano 13, 2019. Disponível em: http:// www.forumseguranca.org.br/wp-content/uploads/2019/10/Anuario-2019-FINAL_21.10.19.pdf. Acesso: 25 mar. 2021.

FOUCAULT, Michel. Microfísica do poder. Organização e tradução de Roberto Machado. Rio de Janeiro: Graal, 2012. 296p.

GORTÁZAR, Naiara Galarraga. A cada hora quatro meninas com menos de 13 anos são estupradas no Brasil. El País, São Paulo, 11 setembro 2019. Disponível em: $\quad$ https://brasil.elpais.com/brasil/2019/09/10/politica/1568134128_017016. html. Acesso em: 25 mar. 2021.

HALL, Stuart. A identidade cultural na pós-modernidade. Rio de Janeiro: DP\&A, 1997.

HOLLANDA, Heloisa B. de. Pensamento feminista hoje: perspectivas decoloniais. Rio de Janeiro: Bazar do Tempo, 2020.

LEAL, Bruno S.; CARVALHO, Carlos A. de; ANTUNES, Elton. Um problema cotidiano [recurso eletrônico]: jornalismo e violência contra mulher no Brasil. Belo Horizonte: Faculdade de Filosofia e Ciências Humanas, 2020.

LEMES, Hélio. Quatro meninas com menos de 13 anos são estupradas a cada hora no Brasil. Diário da Manhã, Goiânia, 7 novembro 2019. Disponível em: https:// www.dm.com.br/cotidiano/2019/11/quatro-meninas-com-menos-de-13-anossao-estupradas-a-cada-hora-no-brasil/. Acesso em: 25 mar. 2021.

LOURO, Guacira L. Gênero, sexualidade e educação: uma perspectiva pós-estruturalista. Petrópolis: Vozes, 1997.

MARTINELLI, Andréa. Recorde de estupros no Brasil escancara negligência com crimes de violência sexual. HuffPost Brasil, São Paulo, 15 setembro 2019. Disponível em: https://web.archive.org/web/20200920213452/https:/www.huffpostbrasil.com/entry/violencia-sexual-dados-estupro_br_5d7c00b0e4b077dcbd5e0acb. Acesso em: 30 maio 2021.

MATHIAS, Maíra; TORRES, Raquel. O novo recorde de violência sexual. Outras Palavras, São Paulo, 11 setembro 2019. Disponível em: https://outraspalavras.net/ outrasaude/recorde-de-violencia-sexual/. Acesso em: 25 mar. 2021.

Miskolci, Richard; Campana, Maximiliano. "Ideologia de gênero": notas para a genealogia de um pânico moral contemporâneo. Sociedade e Estado, Brasília, v. 32, n. 3, p. 725-748, set./dez. 2017. doi:10.1590/s0102-69922017.3203008.

MORAES, Fabiana; SILVA, Marcia V. da. A objetividade jornalística tem raça e gênero: a subjetividade como estratégia descolonizadora. In: XXVIII ENCONTRO ANUAL DA COMPÓS, 2019, Porto Alegre. XXVIII Encontro Anual da Compós. Anais... PUC-RS, Porto Alegre, 2019. p. 1-21. Disponível em: http:// www.compos.org.br/biblioteca/trabalhos_arquivo_5LFXYWXOMDTM6JSBQB BT_28_7677_20_02_2019_17_55_17.pdf. Acesso em: 25 mar. 2021. 
MOUSINHO, Amanda A. Violência de gênero: a percepção social sobre um caso de estupro coletivo por meio da análise dos comentários na página do G1 no Facebook. Cambiassu, São Luís, v. 6, n. 19, p. 34-51, jul./dez. 2016. Disponível em: http://www. cambiassu.ufma.br/cambi_2016.2/violencia.pdf. Acesso em: 25 mar. 2021.

PAUL, Dairan. Fabiana Moraes: “Toda prática jornalística é posicionada e ideológica”. objETHOS, Florianópolis, 19 maio 2020. Disponível em: https://objethos. wordpress.com/2020/05/19/fabiana-moraes-toda-pratica-jornalistica-e-posicionada-e-ideologica/. Acesso em: 25 mar. 2021.

RECUERO, Raquel; SOARES, Pricilla. Violência simbólica e redes sociais no facebook: o caso da fanpage "Diva Depressão". Galáxia, São Paulo, n.26, p. 239-254, dez. 2013. Disponível em: https://revistas.pucsp.br/index.php/galaxia/article/ view/14478/13021. Acesso em: 25 mar. 2021.

REDAÇÃO AN. Polícia prende suspeito de estuprar criança de dois anos em Joinville. NSC Total/A Notícia, Joinville, 11 setembro 2019. Disponível em: https:// www.nsctotal.com.br/noticias/policia-prende-suspeito-de-estuprar-crianca-dedois-anos-em-joinville. Acesso em: 25 mar. 2021.

RIBEIRO, Aline. Brasil registrou recorde de casos de estupro em 2018, segundo estudo. O Globo, São Paulo, 10 setembro 2019a. Disponível em: https://oglobo. globo.com/brasil/brasil-registrou-recorde-de-casos-de-estupro-em-2018-segundo-estudo-23938290. Acesso em: 25 mar. 2021.

RIBEIRO, Aline. Coluna: Sete em cada dez vítimas de estupros em São Paulo são vulneráveis. Época, São Paulo, 1 outubro 2019b. Disponível em: https://epoca.globo.com/coluna-sete-em-cada-dez-vitimas-de-estupros-em-sao-paulo-sao-vulneraveis-23987689. Acesso em: 25 mar. 2021.

RODRIGUES, Mateus. Brasil teve um estupro coletivo a cada duas horas e meia, em 2016; número cresceu 124\% em cinco anos. G1 DF, Brasília, 23 agosto 2017. Disponível em: https://g1.globo.com/distrito-federal/noticia/brasil-teve-um-estupro-coletivo-a-cada-2-horas-e-meia-em-2016-numero-cresceu-124-em-5-anos. ghtml. Acesso em: 25 mar. 2021.

SACHETO, Cesar. Brasil tem quatro meninas de até 13 anos estupradas por hora, diz estudo. R7, São Paulo, 10 setembro 2019. Disponível em: https://noticias. r7.com/sao-paulo/brasil-tem-4-meninas-de-ate-13-anos-estupradas-por-horadiz-estudo-10092019. Acesso em: 25 mar. 2021.

SANTOS, Marli dos; MARADEI, Anelisa. O caso do estupro coletivo no Twitter. In: XXXIX CONGRESSO BRASILEIRO DE CIÊNCIAS DA COMUNICAÇÃO, 2016, São Paulo. XXXIX Intercom. Anais... São Paulo, 2016. p. 1-15. Disponível em: http://portalintercom.org.br/anais/nacional2016/resumos/R11-3140-1.pdf. Acesso em: 25 mar. 2021.

SILVA, Marcia V. da. Masculino, o gênero do jornalismo: modos de produção das notícias. Florianópolis: Insular, 2014. 
SIMÕES, Nataly. Crianças negras são as maiores vítimas de estupro no Brasil. Yahoo! Notícias/Alma Preta, Bauru, 12 setembro 2019. Disponível em: https://br.noticias. yahoo.com/crian\%C3\%A7as-estupros-brasil-anuario-violencia-eca-114808204. html. Acesso em: 25 mar. 2021.

WARKEN, Júlia. 'Inacreditável' é uma das séries mais relevantes e imperdíveis da Netflix. Claudia, São Paulo, 18 setembro 2019. Disponível em: https://mdemulher. abril.com.br/famosos-e-tv/inacreditavel-e-uma-das-series-mais-relevantes-e-imperdiveis-da-netflix/. Acesso em: 25 mar. 2021. 